\title{
Challenges and Innovations of Higher Education Modernization from the Perspective of Big Data
}

\author{
Yu'nan Xie ${ }^{1, *}$ Zhihao Chen ${ }^{1} \mathrm{Han}_{\mathrm{Li}}{ }^{2}$ \\ ${ }^{1}$ School of Public Affairs and Administration, University of Electronic Science and Technology of China, \\ Chengdu, Sichuan, China \\ ${ }^{2}$ Student Affairs Department of Chengdu Technological University, Chengdu, Sichuan, China \\ *Corresponding author. Email: 540629066@qq.com
}

\begin{abstract}
Taking the road to modernization of higher education in the new era is undoubtedly of great theoretical and practical significance. Big data has brought revolutionary changes to higher education, with opportunities and challenges coexisting. This article explores the current situation of higher education in the era of big data and the connotation of education modernization, analyzes the challenges of higher education modernization in the era of big data in technology and education ecology, and finally proposes innovation paths from the three aspects of system construction, education ecology and education ability.
\end{abstract}

Keywords: Big data, Higher education, Modernization, Challenge, Innovation.

\section{INTRODUCTION}

In recent years, the innovation and development of technologies such as big data, cloud computing, and the Internet of Things have changed people's production and lifestyles, and are highly integrated into all fields of society. In the 2021 Government Work Report, Premier Li Keqiang pointed out that innovation should be maintained at the core of China's modernization drive, and scientific and technological self-reliance should be the strategic support of national development. It can be seen that scientific and technological innovation is crucial to China's development. As an important link of modern social education and an important carrier for cultivating innovative talents and creating social value, higher education has also undergone tremendous changes with the advancement of science and technology. Under the wave of the era of big data, further clarifying the status quo, risks and direction of higher education will undoubtedly have positive theoretical and practical significance for China's higher education to improve the quality of education, promote education equity, and accelerate the transformation.

\section{THE STATUS QUO OF HIGHER EDUCATION IN THE BIG DATA ERA}

\subsection{Interpretation of Big Data Background}

With the development of the mobile Internet, informatization and digitization have penetrated into all aspects of social and economic life. Massive amounts of data are generated every day, and these data are huge in volume, diverse in types, and in various forms of expression, including text, pictures, audio, video, and so on. At the same time, data collection methods are gradually enriched, such as sensors, mobile devices, social media, and so on. Various resources and information in social and economic life can be digitized. They are large in scale, diverse in variety, and complex in structure, thus forming big data. Although the amount of data has reached a large order of magnitude, and the data collection is very comprehensive, the value density of these data is very low, and there is less useful information per unit of data. However, when a lot of relevant data are put together, it must reflect the underlying laws of a certain field, and it is necessary to use some effective methods to find these laws. It is the value of big data technology to dig out truly 
meaningful information from massive amounts of data.

Compared with traditional data, big data has $5 \mathrm{~V}$ characteristics: Volume (large capacity), Variety (various types), Velocity (high timeliness), Value (high value), Visualization (visual presentation). [1] Through the means of data mining, the laws and features hidden behind a large amount of data can be found out, and finally these laws and features can be displayed through visual means, and then a basis for evaluation or prediction can be provided. This is the logic of big data.

Big data thinking provides a new perspective for people to look at the world. Each data subject is not only a producer of data, but also a user of data. Everyone in social life produces a lot of data, but the data of a single person is not very meaningful, but when the data of many people are combined to form big data, it is of great significance, because the large amount of data hides the characteristics and laws endowed by human beings, and these are often difficult to be realized without using methods of big data. Academician Li Deyi pointed out that big data has become an important asset of human-beings in the online world. [2] It has its applications in different areas of social life, such as smart cars, unmanned driving, risk prediction, disease control, etc. The applications of big data can be seen everywhere.

\subsection{Higher Education in the Context of Big Data}

The advent of the era of big data has a profound impact on higher education models and higher education concepts. Big data concepts and technologies have gradually become an important force in promoting education reform and education innovation. However, due to the constraints of educational resources, innovation in the field of education is not yet sufficient, and there is still a lot of room for development. For example, students and teachers will generate a lot of data in their studies and work, and the value behind this information can only be visually recognized through exploration, which is what the current education field lacks. Generally speaking, the impact of big data on higher education is mainly reflected in the following three aspects.

\section{DIVERSIFICATION OF EDUCATIONAL INFORMATION RESOURCES}

In the past, the information and data generated by the education process are often very limited, and most of them rely on manual collection and input. Because unstructured data is difficult to process, the form of collecting information is often very simple, mostly structured data. In the era of big data, the teaching process produces a variety of information. The emergence of a variety of unstructured data such as video, audio, text, and images can also be collected and used, which greatly enriches the database. Using appropriate research methods, people can find the huge value hidden behind the data. [3] Different from traditional information analysis, first, the past information collection process will also produce a lot of accompanying information. However, because the information is huge and disorderly, people do not have sufficient storage capacity and reasonable processing methods, so they often ignore the value of the information, for example, the frequency, speed, and time period of teacher evaluation in the student evaluation system. Although it was possible to collect information like this in the past, the information is often not stored and analyzed because a small amount of information is not of research value and there is no suitable method to deal with the huge amount of information, while the value behind it cannot be obtained without using the analysis method of big data. And now, from the perspective of big data, by collecting a large number of student data, especially information and data that have not been paid attention to in the past, some valuable new features can be obtained. Second, the description method has changed a lot. Now it is not only possible to use the methods of descriptive statistics and inferential statistics supported by statistical theories to find the law, but also to find the hidden features behind the data from the perspective of big data. These characteristics are often valuable but difficult to find in the past, which provides a new perspective for the teaching analysis. In addition, rich teaching resources have also emerged. Platforms such as MOOC provide many learning resources. Educational resources have long been not limited to offline teaching resources.

\subsection{Personalization of Educational Pattern Matching}

The application of big data enables college teachers to break through the limitations of their own vision and rely on a larger amount of data to obtain more scientific information, thereby reducing the 
chance of making wrong decisions. [4] For example, online learning platforms can collect more detailed educational behavior data, learner resource learning time, learning resource browsing records, homework, subject performance, etc. The exploration and use of real-time education information can distinguish the characteristics of different students, so as to teach different students in accordance with their aptitude, adjust the classroom mode in time, and adjust the online course design to find more scientific and effective teaching methods. [5] In addition, the teachers can adjust teaching methods in time according to the students' personal information feedback in the classroom. For example, through real-time collection of students' facial expressions, movements, heart rate and other information, teachers can understand the student's listening situation, and find students' classroom difficulties, etc. The personalized teaching model supported by big data has improved the "mass production model" in which everyone uses the same educational method under the traditional teaching model, and weakened the homogeneity of training talents. This is an innovation of the talent training model. [6]

\subsection{Refinement of Education Information Management}

The development of big data has impacted the original education ecology. Traditional educational information management is often just a process of "storing and retrieving". The information is collected and reviewed manually. Massive data can only be stored and waiting to be used, and the information used more is static data that has been collected before. The introduction of big data technology has completely changed the original education ecology. Today's education information management is more of a process of "saving-analysis-utilization". In addition to collecting static information such as student names and ID numbers, the management system also collects daily life data of students. These data are time-efficient and large in quantity. All kinds of data are combined to describe the "data persons". Through the analysis of these data, some high-value results can be obtained. For example, colleges and universities can monitor the situation of poor students in real time based on student travel records, meal card consumption records and other information, so as to provide more effective and timely assistance. In addition, the system can also automatically alarm some behaviors, etc., to achieve refined education information management. [7] The introduction of big data has injected new vitality and energy into the management of colleges and universities.

\section{THE CONNOTATION OF HIGHER EDUCATION MODERNIZATION IN THE BIG DATA ERA}

Education modernization is an important part of national modernization, and it is a concrete manifestation of national modernization in the field of education. From the perspective of the relationship between the two, national modernization points out the direction for education modernization, clarifies goals and provides support, and education modernization provides talents for national modernization, firmly guarantees and lays the foundation. Education modernization is the coordinated and reasonable development of education at all levels, a dynamic process, and an organic combination of modern technology and education. The modernization of education does not require the level of education to reach a certain level, but it means that education should be fully integrated with contemporary technology, adapt to the development of the times, take advantage of technology, and achieve the optimization of the education level. China's educational modernization process has always centered on the fundamental educational issue of "who to train, how to train, and train for whom", focusing on the all-round development of people, and cultivating socialist builders and successors who have a comprehensive development of moral, intellectual, physical, and artistic.

Since the 21st century, China's educational modernization has entered a stage of rapid development. In recent years, with the rise of technologies such as cloud computing, big data, artificial intelligence and blockchain, the modernization of higher education also has new connotations. The modernization of higher education embodies the informatization of higher education, which is mainly manifested in three aspects: The first is the completeness of hardware facilities. Most colleges and universities have already made significant progress in the construction of the Internet, and the construction of related resources has been basically completed, laying a solid foundation for the informatization of education. The second is that the level of information management has been fully improved. For example, all-in-one card management systems and educational administration management systems have been built to form a set of management information systems with a complete logical system. The third is the informatization of higher education. Many high-quality curriculum resources of various universities are transferred online, not limited to 
offline, and can be seen by more people, which increases the scope of knowledge dissemination.

The modernization of higher education implies the modernization of educational methods [8], from the previous offline teaching to a combination of online and offline teaching, providing a richer and more effective way of learning knowledge. The combination of offline and online teaching not only gives students more freedom to choose, and enables them to arrange course time reasonably, but also stimulates students' enthusiasm for learning and improves learning efficiency. In addition, after a large amount of data screening and student feedback, it is easier to distinguish high-quality resources and achieve a virtuous circle. It also provides conditions for educational exchanges between different institutions and different regions, which also reflect the trend of future education methods - no limitation on time and space.

The modernization of higher education implies the modernization of teaching concepts. The traditional teaching concept focuses on teaching, and most of them use the indoctrination method explained by the teacher in the classroom to expand the students' new knowledge, while the students focus on listening in the classroom, listening to the teacher's content and then understanding and learning; however, the modern teaching concept focuses on guidance, and the teacher's function is biased towards cultivating children's learning ability and guiding children to learn. In the classroom, the teacher raises questions, and the students preview before class, discuss independently in class, and study independently after class, from easy to difficult, gradually cultivating personal learning and thinking skills. In class, students focus more on thinking, thinking about the problems raised by the teacher and finding solutions. This method is conducive to guiding students to master the methods and abilities of thinking about knowledge while learning knowledge. In addition, as described above, it is also possible to understand the level of mastery of students and the characteristics of students through data analysis, so that teachers can better understand the situation of different students, and then conduct appropriate guidance. According to the different characteristics of students, different teaching methods are adopted, so that students can be taught in accordance with their aptitude, making every student get the most suitable education and grow up. The future of education is personalized education, which cultivates individualized talents. Each person gets different skills. The way of teaching students in accordance with their aptitude will be a key step in the modernization of teaching concepts.

\section{CHALLENGES OF HIGHER EDUCATION MODERNIZATION IN THE BIG DATA ERA}

In the big data era, although the process of higher education modernization is in full swing and has achieved phased results, it still faces many risks and challenges.

First of all, from a technical point of view, big data can indeed analyze the laws contained in these data, but what if this part of the data itself may be discriminatory? So are decisions made based on such data and results also discriminatory? For example, regions with different levels of economic development use the same data model for assessing poverty. Would it be because this model fits the poverty line of developed areas, and thus the majority of students in colleges and universities in underdeveloped areas are considered to be poor? Of course, if teachers encounter this kind of situation in real life, they can easily identify it and carry out manual intervention. However, the problem is that much of the discrimination in the data itself is difficult to detect manually. When the data returns a certain result, how to determine that the result is reasonable? It is more difficult to determine the rationality of algorithm preferences. Although in many cases the possible results are reasonable and effective, if the results are unreasonable, who is responsible for the decisions made based on the results?

Secondly, from the perspective of informatization, the informatization construction among universities is not comprehensive. The sharing of data can get more precise rules hidden behind the data, but the current degree of data sharing between colleges is very low, causing each school to only use its own students' data, which does not promote the common development of all schools in a certain region [9]. For example, if people want to find the teaching problems in a certain area, it is not enough to rely on the data of a certain school. Because there is no data sharing mechanism, there is no appropriate system and a mechanism for protecting the rights and interests of institutions, and it is impossible for various colleges and universities to take out their own data for unified research, which is easy to derive algorithms with preferences that do not conform to the characteristics of the entire region based on the characteristics of certain colleges and universities themselves. And within each college, the information collection of different departments has 
not been comprehensive, and some colleges and universities only collected data, but did not carry out relevant analysis.

Third, the protection of personal data privacy is also an issue that needs attention. Does the analysis of student big data violate student privacy? Do students have the right not to provide personal information? Or can they not participate in the analysis after providing the information? For example, the question of the consumption detection of poor students mentioned above, does this violate the personal privacy of the relevant students? When privacy protection conflicts with the reform of teaching methods, it is necessary to find a way to balance the interests of both sides.

In addition, the quality construction of the teaching staff is slower than the modernization of higher education. [9] On the one hand, the traditional education model is still widely popular among teachers, and the dependence of teachers and students on traditional education methods has not been completely eliminated; on the other hand, the new ecological model of education puts forward higher standards for the teaching team. Under the influence of two factors, the past experience of the teaching team is no longer adaptable, and new training is needed to make the rational application of big data technology faster.

Finally, the establishment of the big data education ecology has not yet found a suitable methodology, such as what rules should the information sharing mechanism be formed according to, the upstream provision mechanism of big data, the midstream processing mechanism, and the downstream application mechanisms need to master what skills and how well. They are all problems that need to be solved urgently. Although big data methods have been applied in some areas of higher education, the overall situation is still uneven, and the methodology for the establishment and maintenance of the big data education ecology has not yet been formed.

\section{THE INNOVATIVE PATH OF HIGHER EDUCATION MODERNIZATION IN THE BIG DATA ERA}

Looking at higher education from the perspective of big data, data-based thinking is needed. The reason why big data can be widely used is that it provides a method for processing massive and different types of data, and can dig out the knowledge behind the data.
Higher education is a field that generates large amounts of data and complex data types. The application of big data analysis methods is just right. For example, it is possible to conduct an overall analysis by collecting students' evaluation and assessment data on teachers. After analyzing a large number of students' evaluation data, the teachers' teaching characteristics can be classified and summarized, so as to find out which different types the teachers belong to in the minds of students. Similarly, through the research of student information big data, it is also possible to dig out the characteristics of different students, and then formulate exclusive learning plans for them.

In the big data era, to realize the modernization of higher education, it is a must seek truth from facts, and it is necessary to innovate and develop from three aspects: system construction, education ecology, and education capacity.

\subsection{Strengthening System Construction}

Institutional construction is an important part of the establishment of a big data education ecosystem. From the perspective of data analysis, it can be seen that the data analysis process is divided into three stages: data source, data processing and data application. According to the sequence of time, people refer to these three stages as upstream, midstream and downstream respectively.

The upstream mechanism of the data source should do a good job in both information sharing and privacy protection. The information collected between different departments and different colleges is inconsistent, but they are often unwilling to share, and thus miss the opportunity to dig a lot of important information. The upstream should establish a set of relatively reasonable rules, so that different entities can directly reach a consensus agreement, share information under unified constraints, and create greater value. At the same time, it is also a must to pay attention to the privacy protection of data sources. Higher education data should be carried out under the premise that only research can be carried out and no commercial activities should be carried out. At the same time, if the research on the data source does not get the approval to conduct research, it should not be carried out.

In the midstream of data processing, it is necessary to do a good job of reviewing the results, and perform standard data mining after getting the data passed from the upstream of the data. At the same time, it is necessary to set up a dedicated 
algorithm auditor to conduct corresponding research on the results of big data analysis, and infer whether the results use discriminatory data. If so, it is a necessity to adjust the algorithm to eliminate algorithm bias or return the data to the upstream for re-collection. The midstream should exercise stricter control over the algorithm conclusions.

The downstream needs to choose the application of the conclusion based on the actual situation. The conclusion of big data is only to provide a reference for decision-making, and the people downstream of the data must realize that the decision-making power really lies in the hands of people. Decision-making is the result of consideration of multiple interests. You cannot blindly believe in the results of data analysis. It is necessary to make reasonable decisions based on the economic conditions and objective conditions at the time and use appropriate methods.

The upstream, midstream and downstream perform their respective duties and combine organically to form an important part of the education ecology of big data. Among them, clarifying the responsibilities of each part is a vital task. Different parts should not overstep their duties, but coordinate and cooperate with each other to play the role of big data.

\subsection{Cultivating Education Ecology}

The first thing to realize is that the establishment of a big data education ecosystem cannot be completed overnight. It must be a long and tortuous process. In the entire construction process, setbacks will inevitably be encountered. In the process of forming systems and rules, it is a must for people to seek truth from facts and keep advancing with the times.

The education ecology in the era of big data is a complex, organic, and unified system. It is necessary to coordinate the relationship between parts and parts of the ecology, and the relationship between itself and the environment. [10] It is also necessary to build an educational ecology from multiple perspectives. In terms of academic research, transform the previous method of focusing on individual research, focus on building a combination of individual and collective research, online and offline forms, and maximize the use of resources across time and space to improve scientific research communication efficiency. The era of big data has created conditions for the professional division of labor of the scientific research team and the refined management of the faculty. Different aspects of the same research can be entrusted to professionals in different regions. At the same time, the cloud platform also provides the convenience of communication and refined management for the overall research of scientific research. In terms of teaching, online and offline teaching methods are combined, and effective teaching modes such as flipped classrooms are adopted; teaching plans can be appropriately adjusted in accordance with the characteristics of students in data analysis, and new standards can be made by comparing big data plans of multiple universities in the same discipline; teaching management reasonably coordinates resources and pays attention to the role played by the feedback mechanism.

At the same time, it is important to learn from universities in other regions or other countries, cooperate and communicate with different universities, and finally gradually complete the system specifications suitable for the implementation of the soil of their own universities. After the formation of the specifications, they will still change with the changes of the times.

\subsection{Improving Educational Ability}

The schools must focus on cultivating three types of abilities. The first is to strengthen the faculty and staff's basic big data capabilities and basic awareness. They need to guide teachers to rationally, fully and comprehensively understand the changes that big data may bring to education. It is necessary to carry out internal training in colleges and universities to train college teachers to transform from traditional teaching thinking to big data teaching thinking, overcome fear of difficulties, and complete their own transformation with an open and innovative vision. The second is to improve the data literacy of faculty and staff. The new data analysis methods emerging in the era of big data require additional learning. Special training is required for faculty and staff in special positions. Under the premise of mastering basic capabilities, they need to learn additional data analysis knowledge and system operation rules. At the same time, college teachers should increase their awareness of autonomous learning, strengthen their ability to learn independently, and understand the application of big data-related technologies in their own research fields. The third is to strengthen the cultivation of practical skills and innovative capabilities. After completing the transformation of thinking and overcoming the fear of difficulties, teachers gradually realized the learning of modern teaching methods, and applied data analysis methods in work and study life. It is of great significance to 
strengthen practice, learn from experience and lessons in practice, and continue to learn and grow. The teaching emphasizes the cultivation of students' innovative ability to help students adapt to the big data era. And through the means and methods of big data, teachers need to teach students with different characteristics in accordance with their aptitude, and find a suitable training model.

\section{CONCLUSION}

The advent of the big data era provides new thinking and technical means for higher education. At present, the modernization of higher education in China is in a stage of rapid development. During this period, challenges and opportunities coexist. It is a must use strengths and avoid weaknesses, keep pace with the times, and be the first to make good use of the treasure house of big data to promote China's higher education to new heights.

\section{AUTHORS' CONTRIBUTIONS}

Yu'nan Xie is responsible for research design and wrote the part I, Zhihao Chen wrote the main part of manuscript, and Han Li contributed to revising and editing.

\section{REFERENCES}

[1] Meng Xiaofeng, Ci Xiang, Big Data Management: Concepts, Techniques and Challenges [J]. Journal of Computer Research and Development, 2013, 50(01): 146-169. (in Chinese)

[2] Li Deyi, Clustering Into a Breakthrough in Big Data Cognition [N]. China Information Weekly, 2015-04-20(007). (in Chinese)

[3] Xu Xiaodong, Wang Jinhua, Bian Liang, Meng Qian, Data Governance in the Higher Education [J]. Researches in Higher Education of Engineering, 2015(05): 25-30. (in Chinese)

[4] Gan Ronghui, He Gaoda, The Value Orientation and Realization Path of Higher Education Reform in the Big Data Era $[\mathrm{J}]$. China Educational Technology, 2015(11): 70-76+90. (in Chinese)

[5] Yang Xianmin, Tang Sisi, Li Jihong, The Definition, Potential Value and Challenges of Big Data in Education [J]. Modern Distance Education Research, 2016(01): 50-61. (in Chinese)
[6] Kong Jing, Guo Yucui, Guo Guangwu, Technology Enhanced Personalized Learning: The New Trend to Promote Students' Development $[\mathrm{J}]$. China Educational Technology, 2016(04): 88-94. (in Chinese)

[7] Liu Ruili, The Trend and Realization Path of University Education Management in the Era of Big Data $[\mathrm{J}]$. Economic Outlook the Bohai Sea, 2020(05): 138. (in Chinese)

[8] Shi Jinghuan, Ye Zhihong, Hu Jianhua, Xu Xiaozhou, Yang Jie, Li Liguo, Liu Yonggui, Kang Kai, Wang Xiaomei, Gao Xiaojie, Xu Tao, Qu Zhenyuan, Towards 2030: The Path of Modernization of Higher Education in China [J]. China Higher Education Research, 2017(05): 114. (in Chinese)

[9] Zhou Guangli, The Modernization of China's Higher Education Governance: Current Situation, Problems and Countermeasure [J]. China Higher Education Research, 2014(09): 16-25. (in Chinese)

[10] Zhu Yueyun, Research on the Construction of Smart Campus in Colleges and Universities Based on the Educational Big Data Ecosystem [J]. Computer Knowledge and Technology, 2021, 17(03): 37-38+41. (in Chinese) 